\title{
A proof-of-principle study of epigenetic therapy with hydralazine and magnesium valproate plus doxorubicin cyclophosphamide as neoadjuvant therapy for locally advanced breast cancer Claudia Arce ${ }^{2}$, Carlos Perez-Plasencia1 ${ }^{1}$, Aurora Gonzalez-Fierro1, Erik de la Cruz-Hernandez ${ }^{1}$, Alma Revilla-Vazquez ${ }^{3}$, Alma Chavez-Blanco ${ }^{1}$, Catalina Trejo-Becerril ${ }^{1}$, Enrique Perez-Cardenas ${ }^{1}$, Lucia Taja-Chayeb ${ }^{1}$, Enrique Bargallo4, Patricia Villarreal ${ }^{4}$, Teresa Ramirez ${ }^{4}$, Teresa Vela ${ }^{5}$, Myrna Candelaria ${ }^{2}$, Maria F Camargo ${ }^{1}$, Elizabeth Robles ${ }^{2}$ and Alfonso Dueñas-Gonzalez*1
}

Address: ${ }^{1}$ Unidad de Investigación Biomédica en Cáncer, Instituto de Investigaciones Biomédicas, Universidad Nacional Autonóma de Mexico, Instituto Nacional de Cancerología, México, ${ }^{2}$ Division de Investigación Clinica, Instituto Nacional de Cancerología, México, Mexico, ${ }^{3}$ Lab. de Desarrollo de Metodos Analiticos, FES-Cuautitlan, UNAM, Cuautitlan Izcalli, Estado de Mexico, Mexico, ${ }^{4}$ Departmento de tumores mamarios, Instituto Nacional de Cancerología, México, Mexico and ${ }^{5}$ Departmento de patologia, Instituto Nacional de Cancerología, México, Mexico

Email: Claudia Arce - haydeearce@hotmail.com; Alfonso Dueñas-Gonzalez* - alfonso_duenasg@yahoo.com

* Corresponding author

from 24th Annual Meeting of the National Cancer Institute of Mexico Mexico City, Mexico. 14-17 February 2007

Published: 5 February 2007

BMC Cancer 2007, 7(SuppI I):A23 doi:10.1 I86/I47I-2407-7-SI-A23

This article is available from: http://www.biomedcentral.com/I47I-2407/7/SI/A23

(c) 2007 Arce et al; licensee BioMed Central Ltd.

\section{Background}

Aberrant DNA methylation and histone deacetylation participate in cancer development and progression, hence their reversal by inhibitors of DNA methylation and histone deacetylases (HDACs) is undergoing clinical testing in cancer therapy. As epigenetic alterations are common to breast cancer, in this proof-of-concept study, the demethylating hydralazine plus the HDACs inhibitor magnesium valproate were added to neoadjuvant doxorubicin and cyclophosphamide in locally advanced breast cancer to assess their safety and biological efficacy.

\section{Materials and methods}

Patients were typed for acetylator phenotype and then treated with hydralazine at $182 \mathrm{mg}$ for rapid or $83 \mathrm{mg}$ for slow-acetylators, and magnesium valproate at $30 \mathrm{mg} / \mathrm{Kg}$, starting from day -7 until chemotherapy ended which consisted in four cycles of doxorubicin $60 \mathrm{mg} / \mathrm{m}^{2}$ and cyclophosphamide $600 \mathrm{mg} / \mathrm{m}^{2}$, every 21 days. Core needle biopsies were taken from the primary breast tumors at diagnosis and at day 8 of treatment with hydralazine and valproate.

\section{Results}

Sixteen patients were included and received treatment as planed. All were evaluated for clinical response and toxicity and 15 for pathological response. Treatment was welltolerated. The most common toxicity was drowsiness grades $1-2$. Five (31\%) patients had clinical CR and eight $(50 \%)$ PR for an ORR of $81 \%$. No one progressed. One out of 15 operated patients $(6.6 \%)$ had pathological CR and $70 \%$ had residual disease $<3 \mathrm{~cm}$. There was a statistically significant decrease in global $5^{\mathrm{m}} \mathrm{C}$ content and HDAC activity. Hydralazine and magnesium valproate up and down-regulated at least 3-fold, 1091 and 89 genes respectively. Among up-regulated genes there were several tumor suppressor genes including p53. 


\section{Conclusion}

Hydralazine and magnesium valproate produce DNA demethylation, HDAC inhibition and gene reactivation in the primary tumors. This treatment associated with doxorubicin and cyclophosphamide is safe, well-tolerated and seems to increase the efficacy of chemotherapy. A randomized phase III study is ongoing to support the efficacy of the so called epigenetic or transcriptional cancer therapy.

Publish with Bio Med Central and every scientist can read your work free of charge

"BioMed Central will be the most significant development for disseminating the results of biomedical research in our lifetime. " Sir Paul Nurse, Cancer Research UK

Your research papers will be:

- available free of charge to the entire biomedical community

- peer reviewed and published immediately upon acceptance

- cited in PubMed and archived on PubMed Central

- yours - you keep the copyright

Submit your manuscript here:

http://www.biomedcentral.com/info/publishing_adv.asp 